\title{
SCIDiC
}

International Journal of Dentistry and Oral Science (IJDOS)

ISSN: 2377-8075

\section{Orthodontic Management of Patient with Marfan Syndrome - Case Report and Review of the Literature}

\author{
Case Report
}

Kawakami M*, Shimomura T, Kirita T

Department of Oral and Maxillofacial Surgery, Nara Medical University, Nara Medical University, Shijo-cho Kashihara Nara, Japan.

\section{Abstract}

Marfan syndrome (MFS) is a type of connective tissue disorder caused by a mutation of the fibrillin gene and increased TGF- $\beta$ in tissues. This disorder leads to connective tissue fragility, with such clinical manifestations as slender fingers, long limbs, abnormal cardiac valves, and aortic aneurysm development. We present here a case of Class II maxillary protrusion in a 13-year-old male with MFS. The patient underwent orthodontic treatment, including extractions of the upper and lower bicuspids. The treatment achieved a good Class I occlusion with normal overjet and overbite. On the other hand, we found extraordinary craniofacial skeleton development during the post-adolescent period and untreatable marginal gingivitis despite complete plaque control, which might be resulted from connective tissue fragility.

Keywords: Marfan Syndrome; Malocclusion; Fibrillin-1; Transforming Growth Factor Beta; Gingivitis.

Abbreviations: MFS: Marfan Syndrome; Fibrillin 1: FBN 1.

\section{Introduction}

Marfan syndrome (MFS) is an inherited disorder of connective tissue, in which a mutation of the fibrillin 1 gene (FBN1) leads to an increased level of Transforming growth factor beta (TGF- $\beta$ in tissues, with resultant impact on the tissue homeostasis of microand elastic fibers [1]. Clinical manifestations include tall stature, long limbs, mitral valve prolapse, and aortic aneurysm development $[2,3]$. The main dental findings are a high-arched palate and retrognathia, and affected patients exhibit a periodontal ligament and root morphology that might be caused by the associated connective tissue disorder $[4,5]$. Adult MFS patients are characterized by a prolonged face with a posterior positioned mandible, and exhibit maxillary protrusion with labial inclined maxillary incisors and posterior tipped mandibular incisors. Few studies of MFS have examined the specific morphogenetic aspects of the craniofacial complex, or the influence of genetic and environmental factors on clinical management. Here, we describe orthodontic treatment and skeletal changes in a young male with MFS, and discuss specific details related to clinical management of affected patients.

\section{History and Assessment}

A 13-year-old male was referred to the Department of Oral and Maxillofacial Surgery of Nara Medical University Hospital for protrusion of the upper front teeth. The patient had been diagnosed with MFS at the age of 12 years 8 months due to mitral valve prolapse and an aneurysm that developed in the aortic root, for which he underwent heart surgery procedures at the age of 13 years and again at 14 years.

The patient had a convex profile, long face, and retrognathia, including long limbs and slender fingers. An oral examination showed narrow upper and lower dental arches, as well as a posterior crossbite at the first molar, severely protruded upper incisor, and high-arched palate (Figure 1). The molar relationship was Class II on both sides. The overjet and overbite were $+12.0 \mathrm{~mm}$

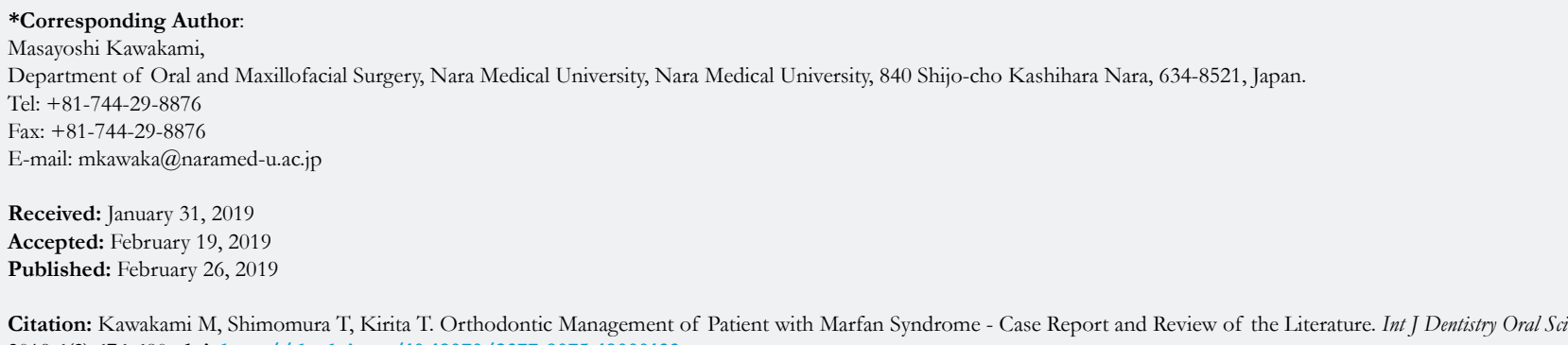

Copyright: Kawakami $\mathbf{M}^{2019}$. This is an open-access article distributed under the terms of the Creative Commons Attribution License, which permits unrestricted use, distribution and reproduction in any medium, provided the original author and source are credited. 
and $+1.6 \mathrm{~mm}$, respectively. Cephalometric examination findings revealed a skeletal Class II jaw relationship $\left(\mathrm{ANB}=7.4^{\circ}\right)$ with a high mandibular plane angle $\left(\mathrm{FMA}=35.5^{\circ}\right.$, gonial angle $\left.=136.5^{\circ}\right)$ (Table 1). The maxillary incisors showed excessive labial protrusion and the lower ones lingual inclination (Figure 2). Both the upper and lower midlines were aligned with the facial midline. Our diagnosis was retrognathia and severe crowding associated with MFS.

\section{Aims of Treatment}

The primary objectives of orthodontic treatment for the patient were retraction of the extremely protruded maxillary incisor, and correction of severe crowding in both the upper and lower arches, in order to achieve a Class I molar and canine relationship on both sides, as well as an ideal overjet and overbite. One of the treatment options considered was retraction of the upper incisor and correction of the Class II molar relationship using fixed appliances, which would be performed after extraction of the upper first bicuspids and lower second premolars. Another plan considered was correction of the maxillary protrusion by surgical advancement of the mandible following presurgical orthodontic treatment without extraction. However, the patient and his parents refused an orthodontic-surgical approach because of the heart disease condition.

Figure 1. Pretreatment facial and oral photographs.

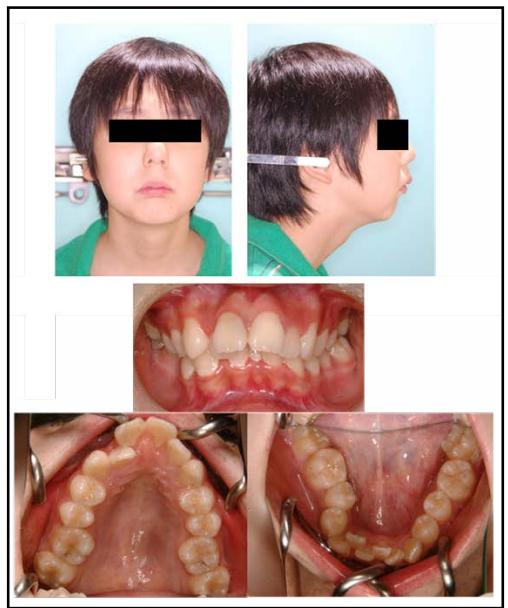

Table 1. Cephalometric analysis findings.

\begin{tabular}{|c|c|c|c|c|}
\hline & Initial & $\begin{array}{c}\text { After } \\
\text { treatment }\end{array}$ & $\begin{array}{c}\text { After } \\
\text { treatment }\end{array}$ & $\begin{array}{c}\text { Normative } \\
\text { mean }\end{array}$ \\
\hline Age & $13 \mathrm{y} 8 \mathrm{~m}$ & $17 \mathrm{y} 5 \mathrm{~m}$ & $19 \mathrm{y} 6 \mathrm{~m}$ & Adult* \\
\hline SNA (dg) & 80.0 & 77.5 & 77.5 & 80.8 \\
\hline SNB (dg) & 72.3 & 74.0 & 74.5 & 77.9 \\
\hline $\mathrm{ANB}(\mathrm{dg})$ & 7.4 & 3.5 & 3.0 & 2.8 \\
\hline Facial angle (dg) & 78.6 & 78.5 & 79.0 & 84.8 \\
\hline FMA (dg) & 35.5 & 38.1 & 38.0 & 30.5 \\
\hline Genial angle (dg) & 136.5 & 135.8 & 137.5 & 130.0 \\
\hline $\mathrm{S}-\mathrm{N}(\mathrm{mm})$ & 69.7 & 74.5 & 74.5 & 72.2 \\
\hline Anterior cranial base (mm) & 69.3 & 75.0 & 75.0 & 73.1 \\
\hline Posterior cranial base $(\mathrm{mm})$ & 48.8 & 50.5 & 53.0 & 39.4 \\
\hline Mand. body length (mm) & 69.6 & 76.3 & 76.0 & 78.6 \\
\hline Anterior face height (mm) & 119.6 & 132.5 & 133.0 & 132.0 \\
\hline Posterior face height (mm) & 79.5 & 87.7 & 88.0 & 84.8 \\
\hline U1 to SN (dg) & 121.0 & 106.0 & 105.0 & 105.9 \\
\hline IMPA (L1 to Mp) (dg) & 93.5 & 96.3 & 93.5 & 93.4 \\
\hline FMIA (dg) & 50.8 & 46.1 & 48.0 & 65.0 \\
\hline Inter-incisal angle & 105.9 & 113.2 & 116.5 & 123.6 \\
\hline Overjet (mm) & 12.0 & 3.0 & 32 & 3.1 \\
\hline Overbite (mm) & 1.6 & 2.5 & 2.4 & 3.3 \\
\hline
\end{tabular}

*Mean for Japanese males with normal growth [12, 15]. 


\section{Treatment Plan}

After performing expansion of the maxillary dental arch with a Quadhelix appliance, a multibracket orthodontic appliance was used for movement of the upper incisors to reduce the large overjet and correct the severe crowding, along with extraction of the upper bicuspids and lower premolars.

\section{Treatment Progress}

At the age of 13 years 10 months, we started maxillary expansion between the upper first molars using the Quadhelix appliance. Six months later, a preadjusted edgewise appliance $(0.018 \times 0.025$ inches) was placed to adjust all maxillary and mandibular teeth, with a 0.016-inch NiTi wire initially used for leveling.

To prevent infective endocarditis, medication with antibiotics and anticoagulants was given during the period of extraction of the upper bicuspids and lower premolars. Thereafter, canine retraction was started, and upper and lower anterior retraction was con- ducted by closing the loops supported by the Quadhelix appliance (Figure 3). Because of repeated hospitalizations related to heart surgery, the patient could only sporadically visit our dental department. Finally, at the age of 17 years 5 months, active treatment was completed (Figure 4, 5). A wraparound retainer was placed on the upper arch and a spring retainer on the lower arch.

\section{Treatment Results}

The patient showed favorable alignment of all teeth after correction of severe crowding. The upper incisors were moved to upright positions, resulting in a normal overjet and overbite, though the maxillary and mandibular midlines were not coordinated. Notably, cephalometric superimposition showed strong forward growth in the anterior cranial base (Figure 6). The increased anterior face height and mandibular body length demonstrated a strong front-downward direction of the mandible during the treatment period, as the ANB angle was decreased from $7.4^{\circ}$ to $3.5^{\circ}$, while the FMA was increased by $2.6^{\circ}$ (Table 1 ).

Figure 2. Pretreatment lateral and frontal cephalometric and panoramic radiographs.

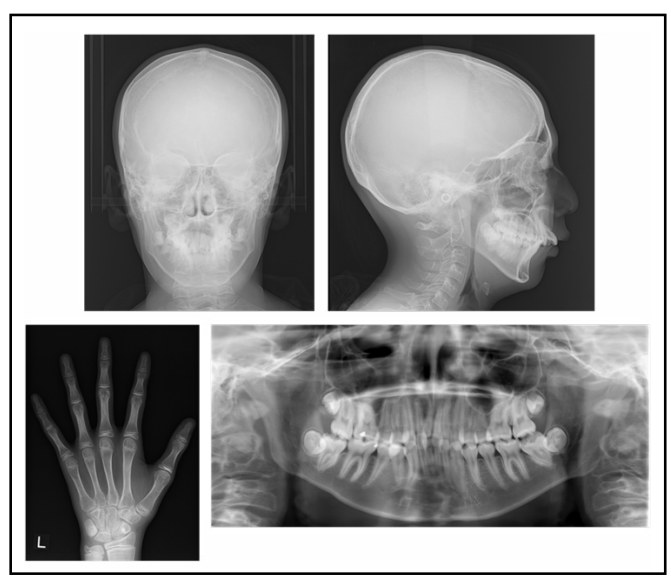

Figure 3. Intraoral photographs showing anterior retraction of upper incisors.

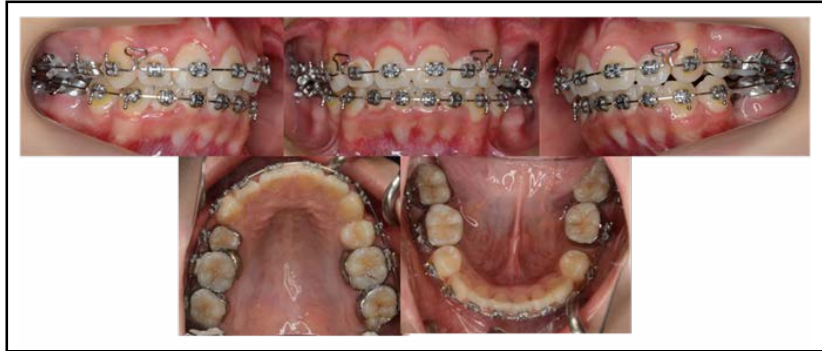

Figure 4. Posttreatment facial and oral photographs.

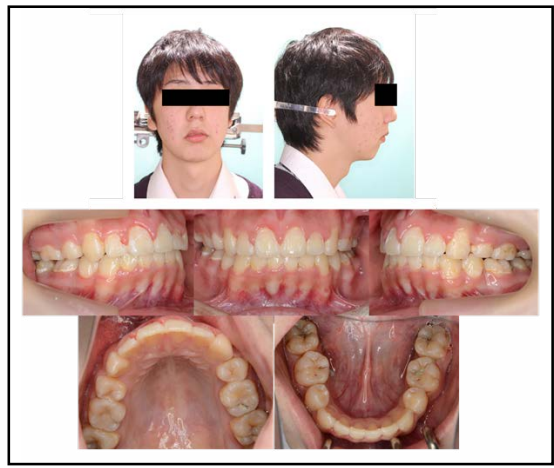


Figure 5. Posttreatment lateral and frontal cephalometric and panoramic radiographs.

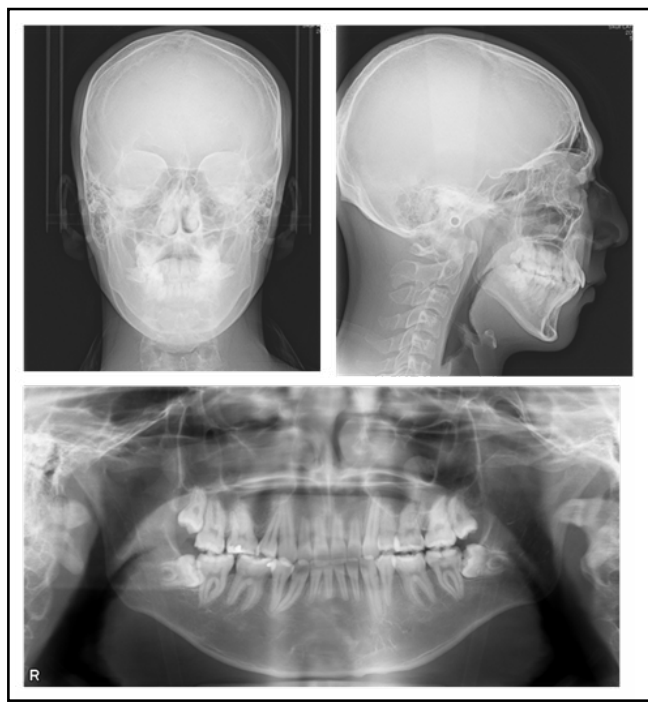

Figure 6. Superimposed cephalometric tracing.

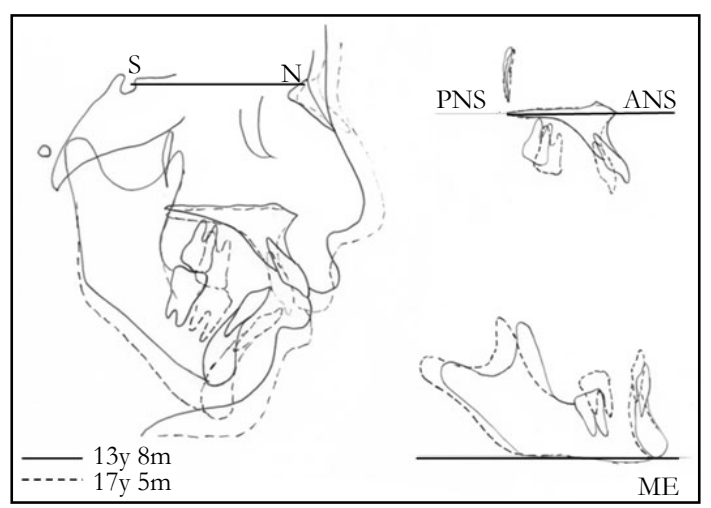

Figure 7. Facial and oral photographs, lateral and frontal cephalometric and panoramic radiographs obtained at 2 years 1 month after treatment.

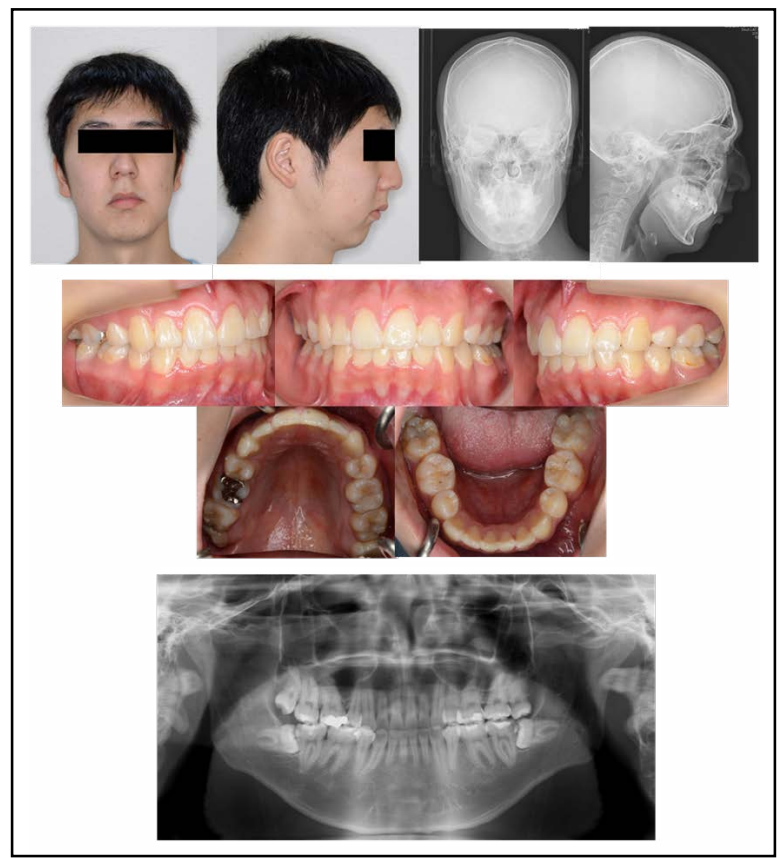




\section{Discussion}

Oral manifestations of MFS are identifiable in intraoral examinations, such as constriction of the maxilla and a high-arched palate, which contribute to teeth crowding and a posterior cross-bite. A dolichofacial face type and skeletal Class II malocclusion are commonly noted in these patients, while severe periodontitis and root resorption, as well as resorption of the condyles of the temporomandibular joint have been reported $[6,7]$.

MFS is an autosomal dominant disease that affects connective tissue. Mutation of FBN1 can be identified in affected cases, resulting in disintegration and fragmentation of connective tissue fibers, leading to tissue fragility and elongation $[1,8]$. The mutation leads to an increased level of TGF- $\beta$ in tissue, resulting in skeletal and cardiovascular manifestations of MFS [1]. TGF- $\beta$ upregulates the expression of elastase and matrix metalloproteases [9], and overproduction of these proteases reduces connective tissue elasticity, with aortic weakness and aneurysm formation developing [2]. An FBN1 mutation in mice was shown to cause interference with wound healing of connective tissue damaged by periodontal disease [10]. Severe periodontitis, and tooth root and condyle resorption might be the result of such reduction in connective tissue elasticity, leading to weakness of periodontal tissue [7]. Indeed the present patient frequently showed gingivitis and gingival bleeding.

We performed orthodontic treatment with extraction of upper and lower bicuspids. Because patients with MFS frequently have cardiovascular system problems, such as dilatation of the ascending aorta, antibiotics are required prior to tooth extraction or band setting to reduce the risk of endocarditis. The present patient had also been given warfarin for prevention of cardiac thrombosis from mitral valve prolapse. Warfarin decreases generation of thrombin, which regulates the conversion of fibrinogen to fibrin [11]. To prevent gingival bleeding after extraction of the upper and lower bicuspids in our patient, the wound was closed with a suture under continuous administration of warfarin. Furthermore, we carefully performed orthodontic tooth movement with a relatively light force and achieved good treatment results, with the final condition the same as that seen in healthy individuals (Figure 7).

This patient demonstrated extraordinary craniofacial skeleton development during the post-adolescent years, while During the 3-year-4-month period of active treatment, the anterior cranial base enlarged by $5.7 \mathrm{~mm}$ and the mandibular body length increased by $6.7 \mathrm{~mm}$ with clockwise rotation of the mandible, which are greater values than seen in normal Japanese (anterior cranial base $(\mathrm{S}-\mathrm{N})=1.9 \mathrm{~mm}$, mandibular body length $=5.1 \mathrm{~mm})$ [12]. The cranial base showed smaller increments of growth and was considered to be stable [13]. The growth changes in this case may have been due to an increased level of TGF- $\beta$, which plays important roles in regulating chondrocyte proliferation and differentiation. Furthermore, TGF- $\beta$ signaling is involved in chondrogenesis by controlling Msx2 expression in undifferentiated cells that give rise to endochondral bone [14]. Other skeletal abnormalities, such as long limbs and long slender fingers, were noted in our MFS patient. These as well as the craniofacial skeleton development might have been results of increased TGF- $\beta$ and reduced elastic fiber contents in musculoskeletal tissue, associated with fibrillin insufficiency.

\section{Conclusion}

The present patient with MFS showed abnormal growth of the craniofacial skeleton, such as the cranial base. Although no significant differences in orthodontic tooth movement were noted, we encountered untreatable marginal gingivitis caused by continued administration of warfarin during and after treatment. MFS is associated with an increased risk of aortic aneurysm development, thus careful observation and management of the oral condition over time are needed. Notable, the growth velocity of the anterior cranial base is greater than that in normal individuals. We concluded that increased TGF- $\beta$ and reduced elastic fiber contents in skeletal tissue might result in these craniofacial condition.

\section{References}

[1]. Benke K, Ágg B, Szilveszter B, Tarr F, Nagy ZB, Pólos M, et al. The role of transforming growth factor-beta in Marfan syndrome. Cardiol J. 2013;20(3):227-234. doi: 10.5603/CJ.2013.0066. PubMed PMID: 23788295.

[2]. Judge DP, Dietz HC. Marfan's syndrome. Lancet. 2005 Dec 3;366(9501):1965-1976. PubMed PMID: 16325700.

[3]. Utreja A, Evans CA. Marfan syndrome - an orthodontic perspective. Angle Orthod. 2009 Mar;79(2):394-400. doi: 10.2319/112707-558.1. PubMed PMID: 19216608.

[4]. De Coster P, Pauw GD, Martens L, De Paepe A. Craniofacial structure in Marfan syndrome: a cephalometric study. Am J Med Genet A. 2004 Dec 15;131(3):240-248. PubMed PMID: 15523638.

[5]. Shiga M, Ogawa T, Ekprachayakoon I, Moriyama K. Orthodontic Treatment and Long-Term Management of a Patient With Marfan Syndrome. Cleft Palate Craniofac J. 2017 May;54(3):358-367. doi: 10.1597/15-068. PubMed PMID: 26237188.

[6]. Straub AM, Grahame R, Scully C, Tonetti MS. Severe periodontitis in Marfan's syndrome: a case report. J Periodontol. 2002 Jul;73(7):823-826. PubMed PMID: 12146542.

[7]. Bilodeau JE. Retreatment of a patient with Marfan syndrome and severe root resorption. Am J Orthod Dentofacial Orthop. 2010 Jan;137(1):123-134. doi: 10.1016/j.ajodo.2007.05.029. PubMed PMID: 20122440.

[8]. von Kodolitsch Y, Robinson PN. Marfan syndrome: an update of genetics, medical and surgical management. Heart. 2007 Jun;93(6):755-760. PubMed PMID: 17502658.

[9]. Chung AW, Au Yeung K, Sandor GG, Judge DP, Dietz HC, Van Breemen C. Loss of elastic fiber integrity and reduction of vascular smooth muscle contraction resulting from the upregulated activities of matrix metalloproteinase-2 and-9 in the thoracic aortic aneurysm in Marfan syndrome. Circ Res. 2007 Aug 31;101(5):512-522. PubMed PMID: 17641224.

[10]. Handa K, Abe S, Suresh VV, Fujieda Y, Ishikawa M, Orimoto A, et al. Fibrillin-1 insufficiency alters periodontal wound healing failure in a mouse model of Marfan syndrome. Arch Oral Biol. 2018 Jun;90:53-60. doi: 10.1016/j. archoralbio.2018.02.017. PubMed PMID: 29547877.

[11]. Fine G, Bauer K, Al-Mohaya M, Woo SB. Successful treatment of ligneous gingivitis with warfarin. Oral Surg Oral Med Oral Pathol Oral Radiol Endod. 2009 Jan;107(1):77-80. doi: 10.1016/j.tripleo.2008.08.007. PubMed PMID: 18996031

[12]. Wada K. A study on the individual growth of maxillofacial skeleton by means of lateral cephalometric roentgenograms. J Osaka Univ Dent Sch. 1977; 22: 239-269.

[13]. Afrand M, Ling CP, Khosrotehrani S, Flores-Mir C, Lagravère-Vich MO. Anterior cranial-base time-related changes: A systematic review. Am J Orthod Dentofacial Orthop. 2014 Jul;146(1):21-32.e6. doi: 10.1016/j.ajodo.2014.03.019. PubMed PMID: 24974995.

[14]. Hosokawa R, Urata M, Han J, Zehnaly A, Bringas Jr P, Nonaka K, et al. TGF- $\beta$ mediated Msx 2 expression controls occipital somites-derived caudal region of skull development. Dev Biol. 2007 Oct 1;310(1):140-153. PubMed PMID: 17727833.

[15]. Okamoto K, Kawahara S. Cephalometric evaluation of craniofacial skeletal growth by Jarabak analysis. J Osaka Odontol Soc. 1992;55:507-524. 